\title{
Atypical neuralgia associated with cervical and thoracic herpes zoster infection
}

\section{Anna Lis-Święty, Anna Michalska-Bańkowska, Agata Zielonka-Kucharzewska}

Department of Dermatology, Medical University of Silesia, Katowice, Poland

Corresponding author: Dr. Anna Lis-Święty, MD., PhD., E-mail: annadlis@neostrada.pl

Sir,

Herpes zoster (HZ) afflicts usually older adults and causes significant suffering from acute and chronic pain, or postherpetic neuralgia (PHN).

We report a case of 79-year-old woman who presented to the Dermatology Department with a 5 days of worsening papulovesicular/vesical rash in the C7-T2 dermatomes on the left side but no other symptoms like pain, itching, hyperaesthesia, paraesthesia (Fig. la-c). Other abnormal findings included: Aype II of diabetes, arterial hypertension, coronary heart disease and atrial fibrillation on long-term therapy with amlodipine, verapamil, ramipril, amiodarone and metformin. HZ infection was considered and the patient was administrated aciclovir at a dose of $800 \mathrm{mg} 5$ times a day for 7 days in the treatment. From the second day of this therapy the new vesicles were not observed, and the skin condition improved. However, after a week from the end of the antiviral treatment severe neuralgia in the left upper limb occurred. The patient received systemic analgesics (paracetamol, tramadol) for 10 days to control the pain. The recurrence of the rash and pain was not observed during the 12 months follow-up.

Painless HZ is not common, but not all that rare, and has been previously reported [1]. Nevertheless, the mechanism of painless HZ is unknown. The varicella- zoster virus (VZV) reactivation leads to inflammatory changes in the dorsal root ganglia, where the focal extravasation, oedema and lympocytic infiltration are formed [2]. The virus penetrates along the sensory nerves to the skin. The acute pain is presumably due to the VZV-induced demyelination

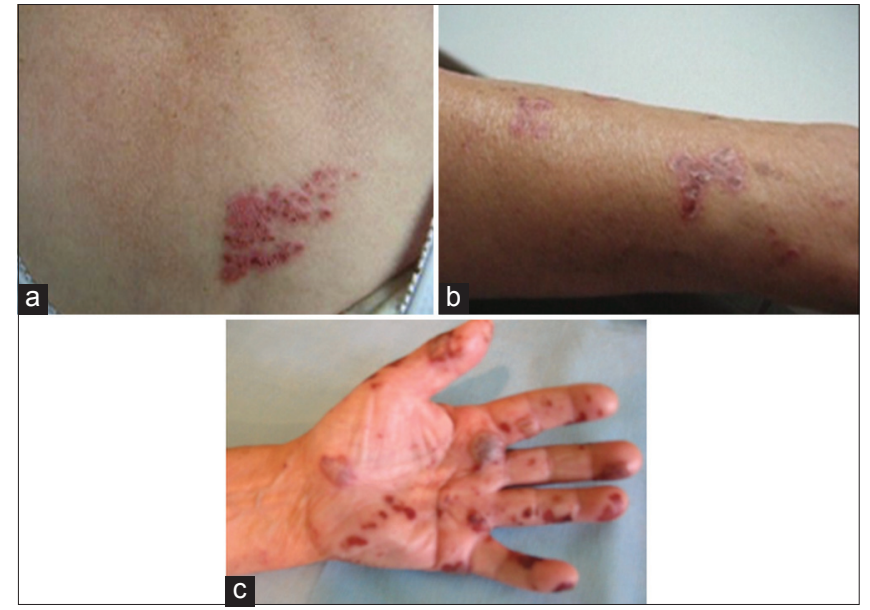

Figure 1: Unilateral papulovesicular/vesical rash on the left side of the chest and left upper limb ( $a$ and $b$ ). Haemorrhagic vesicles and blisters localized on the hand (c).

of sensory nerve fibres. The severity and extent of $\mathrm{HZ}$ skin lesions correlate with the intensity of pain [2].

We described a patient with multiganglionic HZ invloving adjacent ganglia. Despite severe and extensive skin lesions our patient did not complain of pain in the initial phase of HZ infection. As the reason of painless HZ we considered the coexistence of neuropathy linked to diabetes and chronic amiodarone treatment. However, the severe pain occurred a week after the patient was successfully treated with acyclovir. The observed pain resolved in 10 days using systemic analgesics. One could speculate that the lack of pain in acute $\mathrm{HZ}$ was due to a severe VZV viremia, which destroyed ganglia and peripherial nerves and caused abnormal nociception. Therefore, it can be assumed that the pain occurred after the beginning of regenerative processes in the injured ganglia and peripherial nerves. In spite of the predisposing

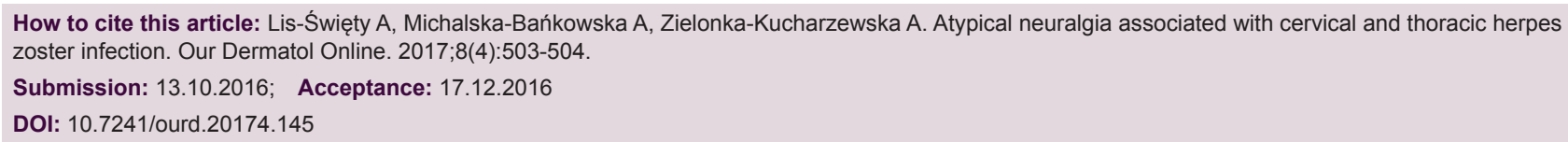


factors as senility, female gender, severe extension of skin lesions, the chronic PHN did not occur [3]. The randomized examinations and meta-analysis proved that the antiviral treatment in HZ significantly reduces the risk of long-lasting pain [4]. Oral administration of aciclovir significantly reduced frequency of PHN [5].

The painless onset of HZ may cause diagnostic problems. Nonetheless, unilateral vesicular rash on an erythematous base with a dermatomal distribution is sufficiently distinctive that a clinical diagnosis of $\mathrm{HZ}$ is usually accurate. The early diagnosis of $\mathrm{HZ}$ and antiviral treatment in our patient probably prevented the chronic PHN.

\section{REFERENCES}

1. Yan C, Laguna BA, Marlowe LE, Keller MD, Treat JR. Herpes zoster duplex bilateralis in an immunocompetent adolescent boy: a case report and literature review. Pediatr Dermatol. 2014;31:341-4.

2. Wollina U, Machetanz J. [Herpes zoster and postherpetic neuralgia]. Hautarzt. 2016;67:653-65.

3. Attal N, Deback C, Gavazzi G, Gorwood P, Labetoulle M, Liard F, et al. Functional decline and herpes zoster in older people: an interplay of multiple factors. Aging Clin Exp Res. 2015;27:757-65.

4. Jang YH, Lee JS, Kim SL, Chi SG, Lee WJ, Lee SJ, et al. Do Interventional Pain Management Procedures during the Acute Phase of Herpes Zoster Prevent Postherpetic Neuralgia in the Elderly?: A Meta-Analysis of Randomized Controlled Trials. Ann Dermatol. 2015;27:771-4.

5. Forbes HJ, Bhaskaran K, Thomas SL, Smeeth L, Clayton T, Mansfield K, et al. Quantification of risk factors for postherpetic neuralgia in herpes zoster patients: A cohort study. Neurology. 2016;87:94-102.

Copyright by Anna Lis-Święty, et al. This is an open access article distributed under the terms of the Creative Commons Attribution License, which permits unrestricted use, distribution, and reproduction in any

medium, provided the original author and source are credited.

Source of Support: Nil, Conflict of Interest: None declared. 